\title{
Enhanced fluoride adsorption by nano crystalline $\gamma$-alumina: adsorption kinetics, isotherm modeling and thermodynamic studies
}

\author{
Prathibha Chinnakoti ${ }^{1}$ Avinash L.A. Chunduri ${ }^{1} \cdot$ Ranganayakulu K. Vankayala $^{1}$ • \\ Sandeep Patnaik ${ }^{1} \cdot$ Venkataramaniah Kamisetti $^{1}$
}

Received: 14 December 2015/ Accepted: 23 May 2016/Published online: 4 June 2016

(C) The Author(s) 2016. This article is published with open access at Springerlink.com

\begin{abstract}
Nano materials in particular nano oxides with enhanced surface area and an excellent catalytic surface serve as potential adsorbents for defluoridation of water. In the present study nano $\gamma$-alumina was synthesized through a simple and low cost, surfactant assisted solution combustion method. As synthesized material was characterized by XRD and FESEM for its phase, size and morphological characteristics. Surface properties have been investigated by BET method. Nano $\gamma$-alumina was further used for a detailed adsorption study to remove fluoride from water. Batches of experiments were performed at various experimental conditions such as solution $\mathrm{pH}$, adsorbent dose, initial fluoride concentration and contact time to test the defluoridation ability of $\gamma$-alumina. Fluoride Adsorption by nano sized $\gamma$ alumina was rapid and reached equilibrium within two hours. The adsorption worked well at $\mathrm{pH} 4.0$, where $~ 96 \%$ of fluoride was found to be adsorbed on adsorbent. It was possible to reduce fluoride levels to as low as $0.3 \mathrm{mg} / \mathrm{L}$ (within the safe limit of WHO: $\leq 1.5 \mathrm{mg} / \mathrm{L}$ ) from an initial fluoride levels of $10 \mathrm{mg} / \mathrm{L}$. This could be achieved using a very small quantity, $1 \mathrm{~g} / \mathrm{L}$ of $\gamma$-alumina at $\mathrm{pH} 4$ within $1 \mathrm{~h}$ of contact time. Defluoridation capacity of nano $\gamma$-alumina was further investigated by fitting the equilibrium data to various isotherm as well as kinetic models. The present study revealed that $\gamma$-alumina could be an efficient adsorbent for treating fluoride contaminated water.
\end{abstract}

Keywords Adsorption · Defluoridation · Kinetics · Isotherms $\cdot$ Thermodynamics $\cdot$ Regenaration

Prathibha Chinnakoti

cprathibha@sssihl.edu.in

1 Nanoscience and Nanotechnology Laboratory, Department of Physics, Sri Sathya Sai Institute of Higher Learning, Prasanthinilayam 515134, AP, India

\section{Introduction}

Fluoride contamination in drinking water due to natural and anthropogenic activities has been recognized as one of the major problems worldwide(Kumar et al. 2011). Optimum concentration of fluoride in water has a protective effect on teeth. At concentrations exceeding a certain limit, it acts as a cumulative toxin, adversely affecting every tissue and organ in the body (Eswar and Devaraj 2011). As per WHO norms, the optimal fluoride intake must be in the range of $0.5-1.5 \mathrm{mg} / \mathrm{L}$ (WHO 1994). Fluoride being most electro negative element bears a negative charge and is attracted by positively charged ions like calcium $\left(\mathrm{Ca}^{2+}\right)$ present in bone and tooth of human body. This further gets converted and deposited as calcium fluoroapatite crystals leading to dental and skeletal fluorosis(Murray 1986).Since water is one of the main sources of fluoride, defluoridation of water is very much necessary. Over the years several defluoridation techniques have been developed and put to test,some at the laboratory level and other at the community level (Eswar and Devaraj 2011). Ease of operation and cost effectiveness are two important features of any technique. Several comparison studies have positioned adsorption technique in the first place for the above mentioned key features. The order of cost effectiveness is adsorption $>$ evaporation $>$ ion exchange $>$ electrodialysis $>$ micro- and ultrafiltration $>$ reverse osmosis $>$ precipitation $>$ distillation $>$ oxidation $>$ solvent extraction (Ali 2012).

In the last two decades, many researchers, have prepared nanosize adsorbents and used for the defluoridation of water. Nanoparticles have proven themselves to be efficient adsorbents compared to traditionally used materials due to their unique properties at nanoscale. The most vital properties of these particles which are responsible for their high 
defluoridation potential are small size, large surface area, catalytic potential, large number of active sites, ease of separation and high reactivity (Ali 2012).

Aluminum ion was considered as a potential acid ion and used frequently for fluoride removal from water. Conventionally, several micron-sized alumina based materials have been extensively used for defluoridation of water. In addition, Various aluminum element based adsorbents Such as Amorphous alumina supported carbon nano tubes ( $\mathrm{Li}$ et al. 2001), nano aluminium oxide hydroxide(Wang et al. 2009), nano Magnesium aluminum mixed Oxide (Shukla et al. 2010), copper oxide coated alumina (Bansiwal et al. 2010), Fe-Al-Ce trimetal oxide (Wu et al. 2007), Al(III) modified calcium hydroxyapatite (Nie et al. 2012) and $\mathrm{Mg}-\mathrm{Al}-\mathrm{CO} 3$ layered double hydroxide ( $\mathrm{Lv}$ et al. 2007) have also been prepared and used for defluoridation of water by many researchers. However a very few reports were available on fluoride adsorption studies on alumina at nano scale.

In the present study nano sized $\gamma$-alumina was synthesized through a simple and low cost, surfactant assisted solution combustion method. As synthesized material was further investigated for physical and chemical characteristics through XRD and FESEM.

Defluoridation potential of $\gamma$-alumina was tested under various experimental conditions, such as $\mathrm{pH}$, contact time, initial fluoride concentrations and adsorbent dose. The obtained data from the experiments were further fitted with different isotherm and kinetic models, to identify the adsorption mechanism (Lv et al. 2013). The results indicated that the nano sized $\gamma$-alumina possessed a maximum defluoridation efficiency of $96 \%$ with the use of very less quantity $1 \mathrm{~g} / \mathrm{L}$ of $\gamma$-alumina within a short amount of time.

\section{Experimental}

\section{Materials}

Analytical Reagent grade chemicals without any further purification were used for material synthesis and adsorption experiments.

\section{Synthesis of nanosized $\gamma$-alumina}

Nanosized gama alumina was synthesized by following our previously reported surfactant assisted combustion method (Chunduri et al. 2014). In typical synthesis $5 \mathrm{~g}$ of aluminum nitrate (oxidizer) and $2 \mathrm{~g}$ of urea (fuel) was mixed with $200 \mathrm{mg}$ CTAB (surfactant). The above redox mixture was dissolved in $2 \mathrm{ml}$ of deionized water and then it is taken into a muffle furnace at $500{ }^{\circ} \mathrm{C}$. The reaction was complete with in 3-4 min by producing white homogenous powder. This powder was collected, washed multiple times using distilled water and ethanol to remove impurities. This sample was dried under vacuum at $60{ }^{\circ} \mathrm{C}$ for a period of $6 \mathrm{~h}$. This was used for all the material characterizations and for all the fluoride adsorption experiments without any surface modifications to the sample.

\section{Characterization of naosized $\gamma$-alumina}

XRD pattern of as synthesized and fluoride adsorbed gama alumina were recorded using powder X-ray diffractometer (PANalytical X'pert Pro MPD) with $\mathrm{Cu} \mathrm{K} \alpha$ radiation $\left(\lambda=1.54 \mathrm{~A}^{\circ}\right)$. The size and surface morphology was evaluated by using FESEM (Zeiss Ultra-55) operated at $10 \mathrm{kV}$. The Brunauer-Emmett-Teller (BET) (Accusorb 2100E, Micromeritics) method was employed to calculate specific surface area, where a cross sectional area of $0.162 \mathrm{~nm}^{2}$ was assumed for the nitrogen molecule.

\section{Batch experiments}

Adsorption experiments were conducted in batch mode in order to investigate the influence of various controlling parameters such as contact time, $\mathrm{pH}$ of the solution, adsorbent dosage and initial concentration of fluoride on defluoridation potential of the adsorbent. To understand the effect of an individual parameter, experiments were performed by varying one parameter at a time while maintaining all the other constant. Concentration of Fluoride ions in water samples was measured by a potentiometric method using fluoride ion selective electrode connected to a Orion potentiometer (Model Orion STARA214). All the experiments were conducted at room temperature $\left(30 \pm 2{ }^{\circ} \mathrm{C}\right)$.

In a typical experiment, known amount of $\gamma$-alumina was added to $20 \mathrm{~mL}$ of fluoride solution of known concentration, in a $100 \mathrm{~mL}$ capped conical flask. The mixture was placed in a mechanical shaker and agitated with a speed of $220 \mathrm{rpm}$ for a fixed period of time. The solution was filtered and concentration of fluoride ions in aqueous solution was measured, when equilibrium was reached.

Adsorption capacity values were calculated from the change in solution concentration using the following expression

$q_{\mathrm{e}}=\left(\frac{C_{0}-C_{\mathrm{e}}}{m}\right) V$

where $C_{0}(\mathrm{mg} / \mathrm{L})$ is the initial concentration, $C_{\mathrm{e}}(\mathrm{mg} / \mathrm{L})$ is the fluoride concentration after equilibration, $V(\mathrm{~L})$ is the volume of solution and $m(\mathrm{gm})$ is mass of the adsorbent.

The percentage adsorption of fluoride ions was calculated by following equation: 
Sorption $\%=\frac{C_{0}-C_{\mathrm{e}}}{C_{0}} \times 100$

where $C_{0}$ and $C_{\mathrm{e}}$ are the initial and equilibrium fluoride concentrations in $\mathrm{mg} / \mathrm{L}$, respectively.

The effect of gama alumina dose on fluoride adsorption capacity was evaluated by varying its dose from 0.1 to $4 \mathrm{~g} /$ $\mathrm{L}$ with an initial fluoride concentration of $20 \mathrm{mg} / \mathrm{L}$. The effect of contact time was examined for stipulated intervals of time from $5 \mathrm{~min}$ to $200 \mathrm{~min}$ for an initial fluoride concentration of $8 \mathrm{mg} / \mathrm{L}$ with an adsorbent dose of $1 \mathrm{~g} / \mathrm{L}$. The effect of $\mathrm{pH}$ was studied by adjusting $\mathrm{pH}$ of $8 \mathrm{mg} / \mathrm{L}$ fluoride concentration solution from $\mathrm{pH} 1$ to $\mathrm{pH} 9$ treated with an adsorbent dose of $1 \mathrm{~g} / \mathrm{L}$. $\mathrm{pH}$ of the solution was adjusted using $0.01 \mathrm{~N} \mathrm{HCl}$ and $0.01 \mathrm{~N} \mathrm{NaOH}$.

To study the adsorption isotherms, experiments were performed by changing initial fluoride concentration from 10 to $100 \mathrm{mg} / \mathrm{L}$, at room temperature $\left(30^{\circ} \mathrm{C} \pm 2{ }^{\circ} \mathrm{C}\right)$ by adding a known amount of nano- $\gamma$-alumina to $20 \mathrm{~mL}$ of each fluoride solution. The solution mixture were kept in a mechanical shaker for $2 \mathrm{~h}$ after which they were filtered and analyzed for residual fluoride concentrations.

\section{Result and discussion}

\section{Characterization}

As synthesized and fluoride adsorbed gamma alumina were characterized by XRD to get an insight of the fluoride adsorption mechanism. Diffraction peaks corresponded to the crystalline phase of $\gamma$-alumina with a cubic structure (JCPDS No.10-0425) as seen in Fig. 1a. The broadened peaks reflect the nano size of the $\gamma$-alumina samples. The XRD spectrum of nano $\gamma$-alumina sample after fluoride
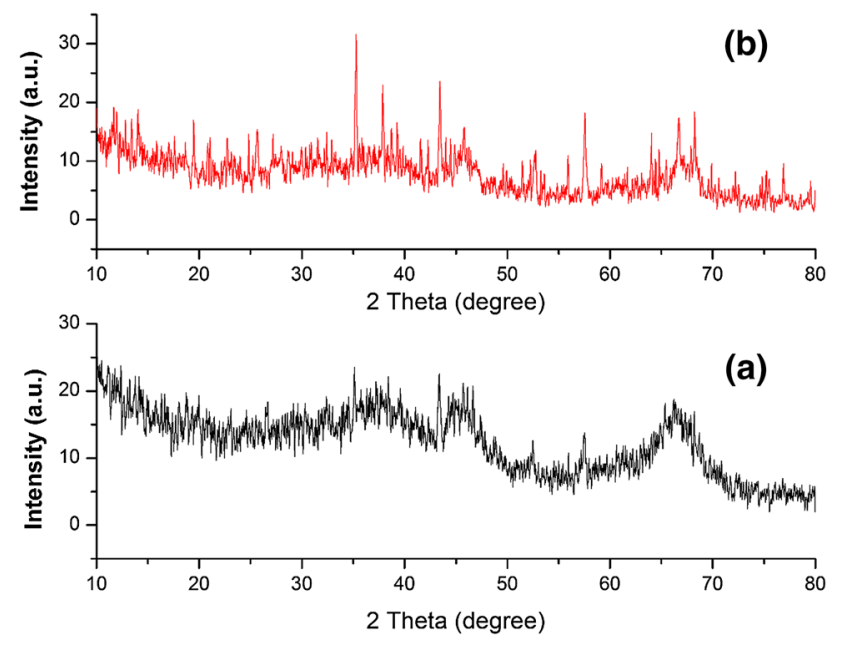

Fig. 1 XRD patterns of gamma alumina (a) and fluoride adsorbed gama alumina (b) adsorption (Fig. 1b) exhibited changes in its crystalline structure due to the formation of various aluminium fluoride salts. This could be ascribed to predominate chemisorption process in fluoride adsorption.

The surface morphology of as synthesized gamma alumina and fluoride adsorbed gama alumina was shown in the Fig. 2a,b. These samples exhibited more irregular morphology due to the harsh conditions (high temperature) of synthesis procedure. The sample after fluoride adsorption exhibited slight change in its size due to the adsorption of fluoride ions forming various fluoride salts. The surface area of gamma alumina, estimated by BET method was found to be $221 \mathrm{~m}^{2} / \mathrm{g}$ which is very high compared to that of commercially available gama alumina $\left(150 \mathrm{~m}^{2} / \mathrm{g}\right)$.

\section{Equilibrium time and Adsorption kinetics}

Equilibrium time is the minimum time for which adsorbent needs to be in contact with fluoride ions in order to obtain
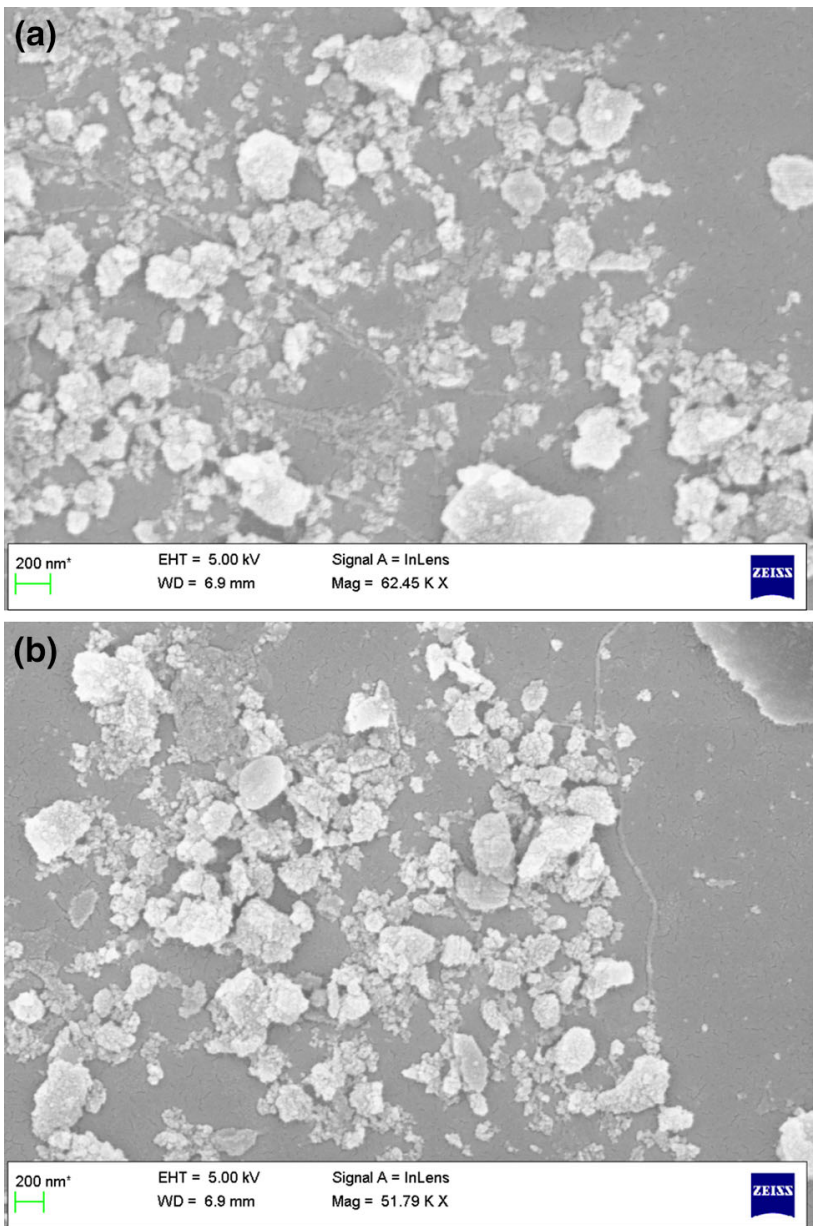

Fig. 2 FESEM images of nano gama alumina $\mathbf{a}$ before and $\mathbf{b}$ after fluoride adsorption

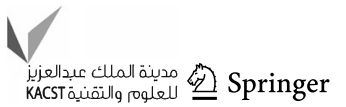




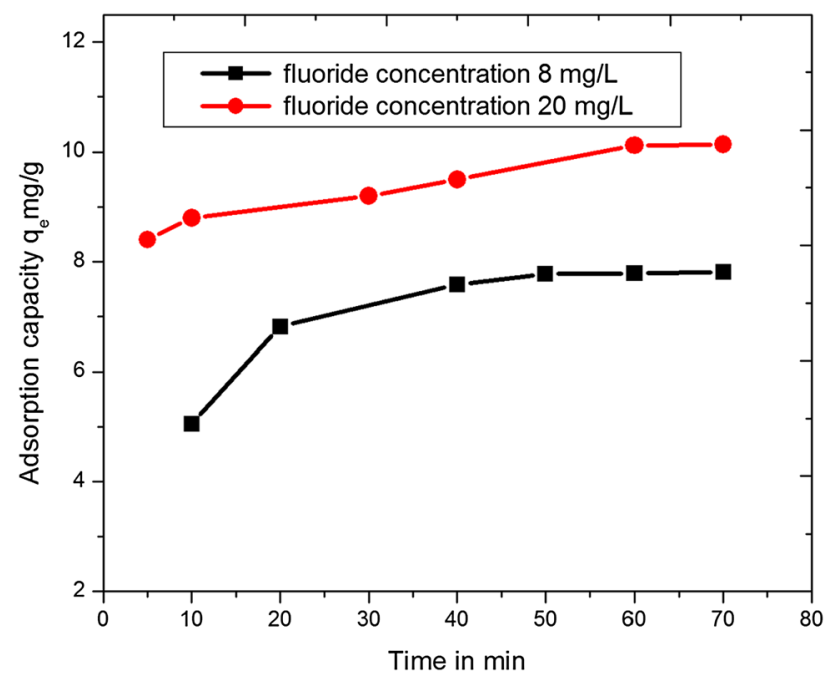

Fig. 3 Adsorption capacity of nano sized $\gamma$-alumina as a function of contact time $\left(T=30^{\circ} \mathrm{C}, \mathrm{pH} 4.0\right.$, adsorbent dose $\left.=1 \mathrm{~g} / \mathrm{L}\right)$

maximum fluoride removal. Figure 3 illustrated the fluoride uptake capacity of $\gamma$-alumina as a function of reaction time for two different fluoride ion concentrations 8 and $20 \mathrm{mg} / \mathrm{L}$ at $\mathrm{pH} 4$ with an adsorbent dose of $1 \mathrm{gm} / \mathrm{L}$. It was evident from the graph that, maximum of fluoride was adsorbed during the first $20 \mathrm{~min}$. From the shape of the kinetic curve, it was evident that the fluoride adsorption onto $\gamma$-alumina was a two-step process, i.e. initial rapid adsorption during the first $20 \mathrm{~min}$ and slow rate of adsorption until the equilibrium was reached (Nie et al. 2012). The adsorption of fluoride ions on to $\gamma$-alumina, reached equilibrium in $60 \mathrm{~min}$. From this study it can be inferred that nano sized $\gamma$-alumina was able to remove fluoride ions from water in a very short duration of time as compared to many micron sized aluminium based adsorbents where an equilibrium time of 5-6 h was reported earlier (Ghorai and Pant 2005).

Estimating the rate of adsorption in any adsorption process is the most important factor in adsorption system design. In order to explore on the adsorption mechanisms, a number of kinetic models have been suggested. In the present work the reaction based models pseudo first-order, pseudo second-order and diffusion based intra particle diffusion model were employed to test the kinetic data.

Linear form of pseudo-first-order model described by Lagergren can be presented as follows(Demirbas et al. 2004):

$\log \left(q_{\mathrm{e}}-q_{t}\right)=\log q_{\mathrm{e}}-\frac{k_{1}}{2.303} t$

where $q_{\mathrm{e}}$ (in $\mathrm{mg} / \mathrm{g}$ ) is the fluoride adsorbed per unit mass of adsorbent at equilibrium, $q_{\mathrm{t}}$ (in $\mathrm{mg} / \mathrm{g}$ ) is the fluoride adsorbed per unit mass of adsorbent at any time $t$ and $K_{1}$ is the rate constant of adsorption.
$K_{1}$ and $q_{\mathrm{e}}$ were determined from the linear regression analysis of the plot $\log \left(q_{\mathrm{e}}-q_{t}\right)$ vs time (Fig. 4).

Pseudo-second-order kinetics was expressed in linear form as given below. (Ho and McKay 1999):

$\frac{t}{q_{t}}=\frac{1}{k_{2} q_{\mathrm{e}}^{2}}+\frac{t}{q_{t}}$

where $q_{\mathrm{e}}(\mathrm{mg} / \mathrm{g})$, the equilibrium adsorption capacity and $K_{2} \quad$ (g/mg min), the second order constants can be calculated using the slope and intercept of the linear fit of the plot $t / q_{t}$ versus $t$ (Fig. 5). The kinetic parameters $k_{1}$, $k_{2}$ and correlation coefficients $\left(R^{2}\right)$ of the two kinetic models were presented in Table 1 . The closer observation of the data in Table 1 revealed that there was a strong disagreement between the experimental $q_{\mathrm{e}}$ value and calculated $q_{\mathrm{e}}$ values from pseudo-first-order model. This indicated that the adsorption of fluoride ion does not follow first-order kinetics. From the Table 1 it was also evident that the pseudo second order model offered a better fit to the experimental data with higher correlation coefficient $R^{2}$ value of 0.99 when compared with the pseudo first order reaction. Moreover $q_{\mathrm{e}}$ experimental and $q_{\mathrm{e}}$ calculated values, for the pseudo second order model were close to each other. Hence, the pseudo-second-order model was a better descriptor of the adsorption kinetics of fluoride ion by nano sized $\gamma$-alumina similar results were reported earlier (Prathibha et al. 2015). These results indicated that the overall rate of the fluoride ion adsorption was most likely to be governed by the chemisorption process. The fluoride removal mechanism by $\gamma$-alumina has been shown to have anion exchange mechanism wherein $\mathrm{OH}^{-}$is replaced with $\mathrm{F}^{-}$ion, by the earlier researchers(Hu et al.

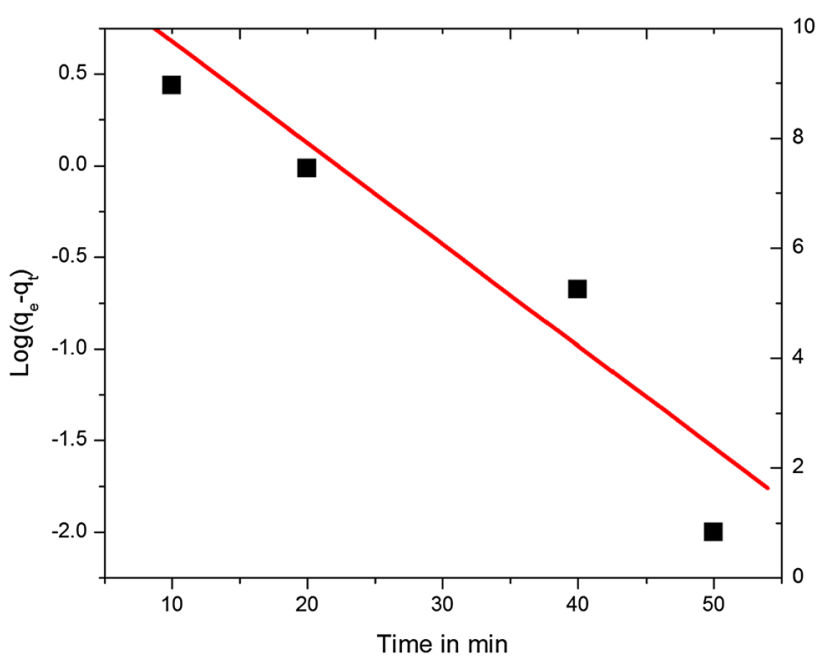

Fig. 4 Linear plot of pseudo-first order kinetics for fluoride adsorption on nano sized $\gamma$-alumina [conditions: $\mathrm{pH} 4303 \mathrm{~K}, \mathrm{~F}-10 \mathrm{mg} / \mathrm{L}$ nano sized $\gamma$-alumina dose $1.0 \mathrm{~g} / \mathrm{L}]$ 


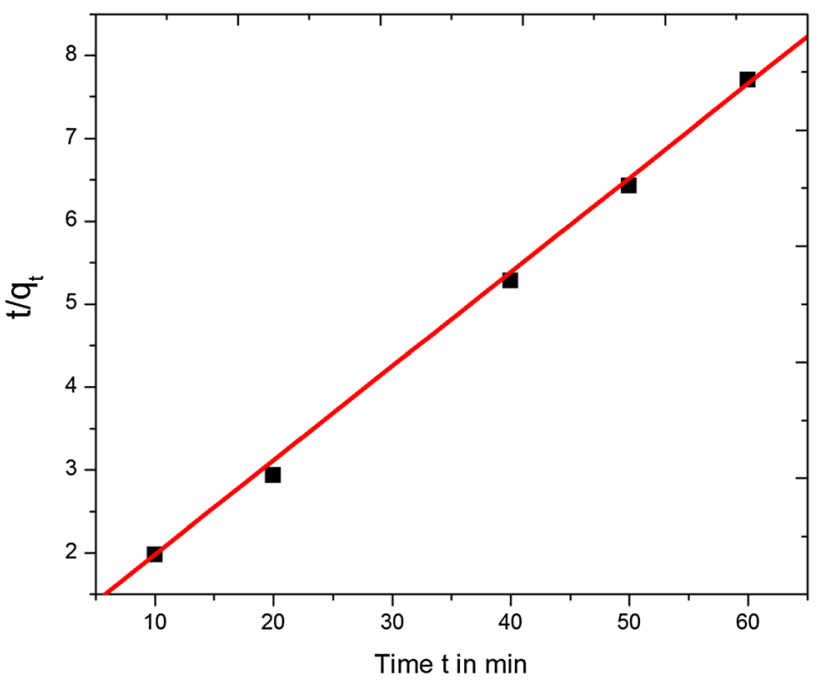

Fig. 5 Linear plot of Pseudo-second order kinetics for fluoride adsorption on nano sized $\gamma$-alumina [conditions: $\mathrm{pH} 4,303 \mathrm{~K}$, F-10 mg/L nano sized $\gamma$-alumina dose $1 \mathrm{~g} / \mathrm{L}]$

2005). These two ions form Aln $F_{\mathrm{m}}(\mathrm{OH})_{3 \mathrm{n}-\mathrm{m}}$ complexes with $\mathrm{Al}(\mathrm{III})$ ions as shown below in $\mathrm{Eq} 5$.

$n \mathrm{Al}_{(\mathrm{aq})}^{3+}+3 n-m \mathrm{OH}_{(\mathrm{aq})}^{-}+\mathrm{mF}_{(\mathrm{aq})}^{-} \rightarrow \mathrm{Al}_{\mathrm{n}} \mathrm{F}_{\mathrm{m}}(\mathrm{OH})_{3 \mathrm{n}-\mathrm{m}(\mathrm{s})}$

Zhang et al. have investigated fluorination on the $\gamma$ alumina surface by multinuclear MAS NMR spectroscopy (Zhang et al. 2002). The spectroscopic results confirmed that, fluorine was adsorbed on to the alumina surface through the substitution of surface hydroxyl groups without breaking the $\mathrm{Al}-\mathrm{O}-\mathrm{Al}$ bonds. At higher fluoride loadings, bridging $\mathrm{Al}-\mathrm{O}-\mathrm{Al}$ bonds were found to be broken to sorb more fluoride under the strong electron-withdrawing effect of fluorine (Kumar et al. 2011). It is likely that nano $\gamma$ alumina could have similar mechanism for fluoride removal.

\section{Diffusion based model}

"Adsorption mechanism is a multi-step process. The first step involves the diffusion of the sorbate from the aqueous phase to the adsorbent surface. In the next step diffusion takes place into the internal pores and voids within the matrix of the absorbent" (Zhang et al. 2011). In the present

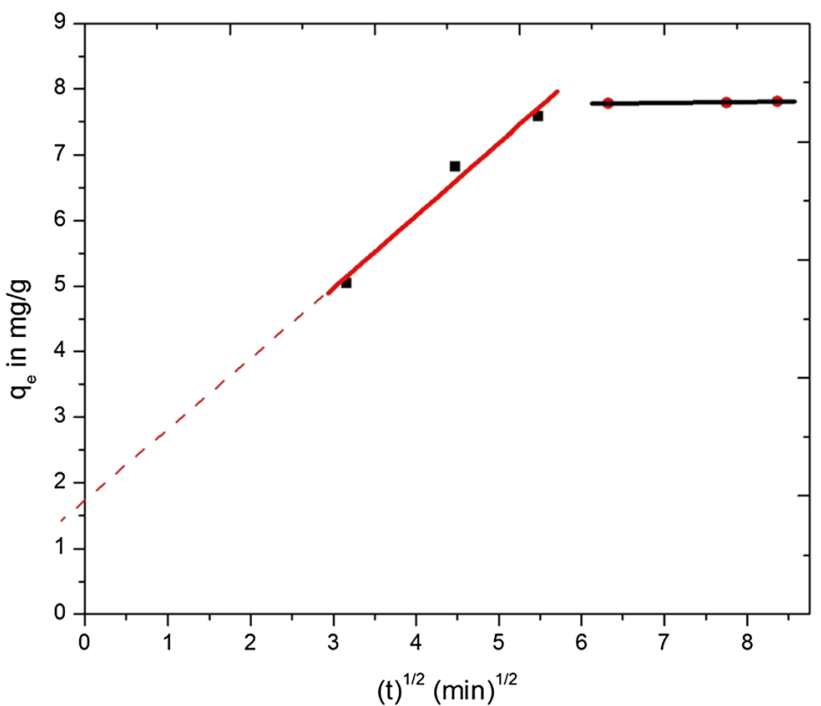

Fig. 6 Plot of Intra-particle diffusion for fluoride adsorption by nano sized $\gamma$-alumina

case the kinetic experimental results were analyzed by the Weber's intra particle diffusion model which is expressed as follows:

$q_{t}=K_{\mathrm{id}} \sqrt{t}+C$

where $C(\mathrm{mg} / \mathrm{g})$ is the intercept and $k_{\mathrm{id}}(\mathrm{mg} / \mathrm{g}) \mathrm{min}^{-1 / 2}$ the intra particle diffusion rate constant is the slope of the plot $q_{t}$ vs $\sqrt{t}$.

In a Weber-Morris model, if, the intra particle diffusion is the only rate-limiting step, graph of $q_{t}$ vs $\sqrt{t}$ is a straight line passing through the origin. It is not always the same for every adsorption system as adsorption kinetics may be controlled by adsorbate film and intra particle diffusion simultaneously. The value of intercept $C$ of the plot reflects the boundary layer effect. The larger the intercept, the greater is the contribution of the surface adsorption in the rate controlling step.

In the present investigation the plot of $q_{t} \mathrm{vs} \sqrt{t}$ for the adsorption of fluoride ion on to nano sized $\gamma$-alumina was not a straightline passing through the origin as shown in Fig. 6.The data points represented bi-linear plots for the experimental data. The deviation of straight lines from the origin may be attributed to the difference between the rate of mass transfer in the initial and final stages of adsorption

Table 1 Kinetic Rate constants and correlation coefficients of studied models

\begin{tabular}{|c|c|c|c|c|c|c|c|c|c|}
\hline \multirow[t]{2}{*}{$q_{\mathrm{e}, \exp } \mathrm{mg} / \mathrm{g}$} & \multicolumn{3}{|c|}{ Pseudo-first-order parameters } & \multicolumn{3}{|c|}{ Pseudo-second-order-parameters } & \multicolumn{3}{|c|}{ Intra particle diffusion model } \\
\hline & $K_{1}\left(\min ^{-1}\right)$ & $R^{2}$ & $\mathrm{q}_{\mathrm{e}, \mathrm{cal}}(\mathrm{mg} / \mathrm{g})$ & $K_{2}(\mathrm{~g} / \mathrm{mg} \min )$ & $\mathrm{q}_{\mathrm{e}, \mathrm{cla}}(\mathrm{mg} / \mathrm{g})$ & $R^{2}$ & $K_{\text {id }}(\mathrm{mg} / \mathrm{g})\left(\min ^{-1 / 2}\right)$ & $C(\mathrm{mg} / \mathrm{g})$ & $R^{2}$ \\
\hline 8.0 & 0.127 & 0.90 & 17.06 & 0.02678 & 8.8 & 0.99 & 1.1 & 1.65 & 0.98 \\
\hline
\end{tabular}


(Sun et al. 2015). Such a deviation also indicated that the mechanism of fluoride removal on nano sized $\gamma$-alumina to be complex and both surface adsorption as well as intra particle diffusion contributed to the rate determining step. The calculated intra particle diffusion coefficient $k_{\text {id }}$ value was listed in Table 1. Similar phenomenon was observed in the adsorption of fluoride ion on to nano structured hydroxi apatite (Poinern et al. 2011)

\section{The effect of pH}

One of the vital influencing parameters in the adsorption process was the initial $\mathrm{pH}$ of fluoride solution and hence its effect $\mathrm{o}$ of $\mathrm{n}$ fluoride uptake capacity of nano sized $\gamma$ alumina was observed over a pH range (2-9) (Devi et al. 2014). Other parameters kept constant during this study were: adsorbent dose of $1 \mathrm{~g} / \mathrm{L}$, initial fluoride concentration $8 \mathrm{mg} / \mathrm{L}$, contact time $2 \mathrm{~h}$, temperature $\left(30 \pm 2{ }^{\circ} \mathrm{C}\right)$. Obtained results were graphically presented in Fig. 7. It was observed that fluoride sorption increased with the increase in $\mathrm{pH}$ from 2 to 4 and began to slightly decrease from $\mathrm{pH} 4$.

At $\mathrm{pH}<\mathrm{pHzpc}$ the surface charge is positive, favoring anion adsorption. At $\mathrm{pH}>\mathrm{pHzpc}$ the superficial charge is negative, favoring cation adsorption. The zero point charge (pHzpc) is the $\mathrm{pH}$ at which the net electric charge of the adsorbent surface is zero (Mohan et al. 2012). To determine the pHzpc of $\gamma$-alumina, known amount of the $\gamma$ alumina was added into deionized water samples of different initial $\mathrm{pH}$. The flasks were agitated intermittently for $48 \mathrm{~h}$ at room temperature. After equilibration the final $\mathrm{pH}$ of each sample was measured. The change in $\mathrm{pH}$ $\left(\Delta \mathrm{pH}=\mathrm{pH}_{\mathrm{f}}-\mathrm{pH}_{\mathrm{i}}\right)$ was plotted against initial $\mathrm{pH}$ as $\mathrm{sh}$

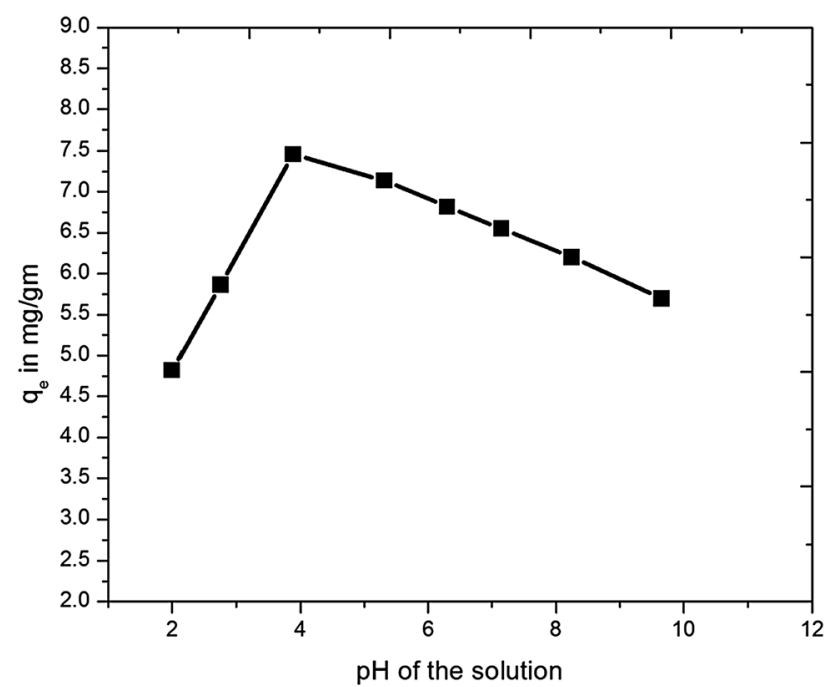

Fig. 7 Influence of $\mathrm{pH}$ on fluoride adsorption capacity of nano sized $\gamma$-alumina own in Fig. 8. It was evident from the Fig. 8 that at $\mathrm{pH}_{\mathrm{i}}=6.5, \Delta \mathrm{pH}$ was zero. Hence the $\mathrm{pH}_{\mathrm{ZPC}}$ of $\gamma$-alumina was estimated as 6.5.The higher fluoride adsorption from $\mathrm{pH} \quad 2-4$ was attributed to the electrostatic attraction between the positively charged adsorbent surface and highly electro negative fluoride ions. The decrease trend in fluoride adsorption from $\mathrm{pH} 4.0$ was due to the reduced positive charge density of the adsorbent surface. Beyond $\mathrm{pH}$ 6.5, the surface was deprotonated, acquired a negative charge and hence repelled fluoride anions. This further resulted in decreased adsorption.

\section{The effect of adsorbent dosage}

The degree of fluoride adsorption by $\gamma$-alumina sample as a function of adsorbent dose was studied by varying adsorbent dose from 0.1 to 4 to a $20 \mathrm{mg} / \mathrm{L}$ concentration of fluoride solution at $\mathrm{pH} 4$. Contact time was maintained to be $2 \mathrm{~h}$ for each observation. Obtained results of this study were graphically presented in Fig. 9. It was evident from the graph that, fluoride adsorption enhanced from 35 to $94 \%$ with the increase of gama alumina dose from 0.1 to $4 \mathrm{~g} / \mathrm{L}$ and remained fairly constant for further raise in the gama alumina dosage. This was presumably due to increase in available reaction sites for fluoride ion adsorption on surface of the adsorbent with increase in the adsorbent dose. Adsorption reached saturation, when the adsorbent dose was further increased. This could be due to the availability of limited fluoride ions, compared to that of adsorbent sites. As per the above study $4 \mathrm{~g} / \mathrm{L}$ of $\gamma$-alumina dose exhibited an appreciable fluoride removal capacity of $94 \%$ from a high initial fluoride concentration of $20 \mathrm{mg} / \mathrm{L}$.

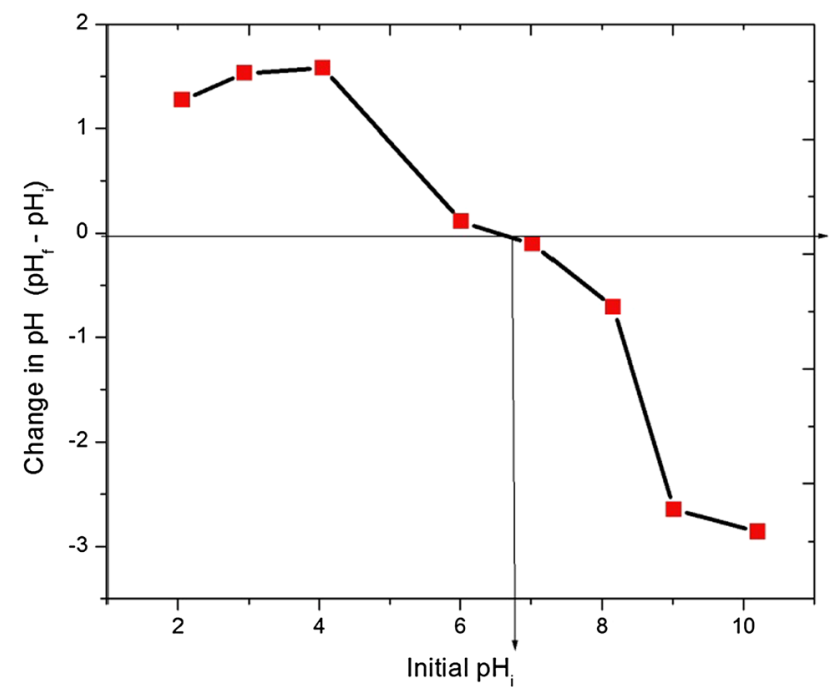

Fig. $8 \mathrm{pH}_{\mathrm{zpc}}$ of nano sized $\gamma$-alumina 


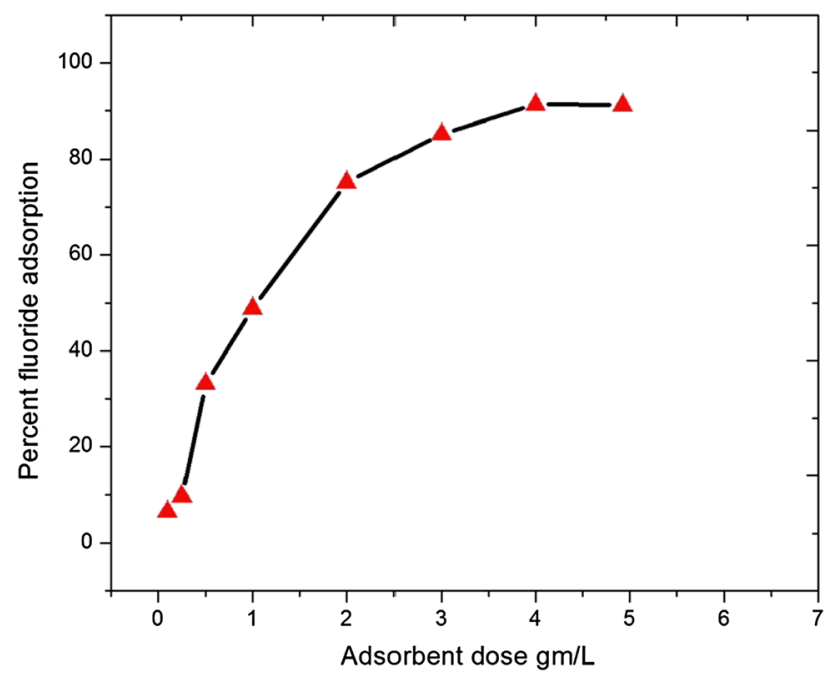

Fig. 9 Effect of Adsorbent dose on fluoride adsorption by nano sized $\gamma$-alumina

\section{Adsorption isotherm study}

Adsorption isotherms are vital, to get an insight into adsorption process. They describe the distribution of the adsorbate between the solution and the adsorbent when the adsorption process reaches an equilibrium state (Poinern et al. 2011). Fluoride adsorption by nano sized $\gamma$-alumina was studied by varying the initial fluoride concentration from 10 to $100 \mathrm{mg} / \mathrm{L}$ (Fig. 10).

It was observed that with increase in initial fluoride concentration, fluoride adsorption capacity (fluoride uptake capacity by unit mass of an adsorbent $\mathrm{mg} / \mathrm{g}$ ) increased and then reached a plateau. This should be due to the increase in number of available fluoride ions for the adsorption by a

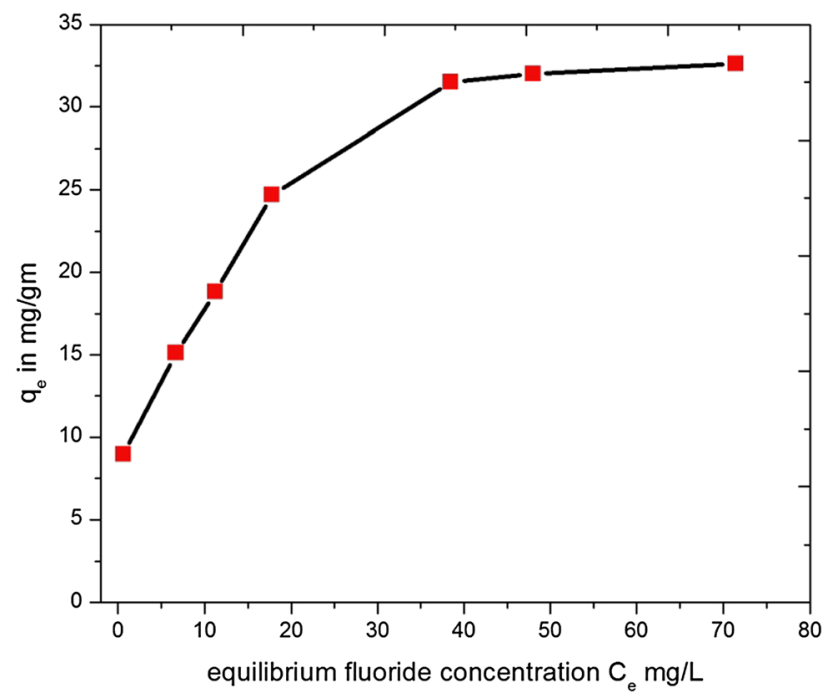

Fig. 10 Fluoride Adsorption isotherm of $\gamma$-alumina [conditions: $\mathrm{pH}$ $4,303 \mathrm{~K}$, contact time $2 \mathrm{~h}, \gamma$-alumina dose $1.0 \mathrm{~g} / \mathrm{L}$ ] fixed mass of an adsorbent as fluoride concentration increased and plateau was due to the saturation of all the active sites of the adsorbent surface. Similar results were reported by many researchers earlier (Dayananda et al. 2014)

"The removal of fluoride in equilibrium adsorption process can be described by several isotherms. Every isotherm is based on a set of assumptions related to the homogeneity of adsorbents, the type of coverage, and the possibility of interaction between the adsorbent species" (Liu et al. 2015). In the present work the sorption isotherms were studied using the Langmuir (Langmuir 1916) and Freundlich (Freundlich 1906) models.

Langmuir isotherm was developed based on the following assumptions

(1) Uniform Adsorbent surface. (2) Occurrences of adsorption on homogeneous sites of the adsorbent and (3) adsorbed molecules do not interact with each other. "Langmuir isotherm is applied when adsorption is limited to monolayer formation of adsorbate on the surface of adsorbent" (Prathibha et al. 2015). The most popular linear expression of isotherm is as follows:

$\frac{1}{q_{\mathrm{e}}}=\left(\frac{1}{b q_{\max }}\right) \frac{1}{c_{\mathrm{e}}}+\frac{1}{q_{\max }}$

where $q_{\mathrm{e}}(\mathrm{mg} / \mathrm{g}), c_{\mathrm{e}}(\mathrm{mg} / \mathrm{L})$, and $b(\mathrm{~L} / \mathrm{mg})$ are equilibrium sorption capacity, equilibrium fluoride concentration and the Langmuir isotherm constant, respectively. The $q_{\max }$ represents theoretical maximum adsorption capacity of the adsorbent. It indicates a practical limit to adsorption capacity of an adsorbent when there is monolayer of adsorbate formed on its surface.

The $q_{\max }$ and $\mathrm{b}$ were computed from the linear regression analysis of the plot of $1 / c_{\mathrm{e}}$ vs $1 / q_{\mathrm{e}}$. The same plot was graphically represented in Fig. 11. The Langmuir constants $b$ and $q_{\max }$, were found to be $0.836 \mathrm{~L} / \mathrm{mg}$ and $26.35 \mathrm{mg} / \mathrm{g}$, respectively. The viability of the isotherm was measured by the value of separation parameter $R_{\mathrm{L}}$ and the same was calculated by using the following expression.

$R_{\mathrm{L}}=\frac{1}{1+b C_{i}}$

where $b$ is the Langmuir isotherm constant, $C_{i}$ initial fluoride concentration $(\mathrm{mg} / \mathrm{L})$. Adsorption is considered as favorable for values of $R_{\mathrm{L}}$ less than one. In the current investigation value of $R_{\mathrm{L}}$ was found to be less than one for all fluoride concentrations studied in the experiment. This indicated favorable adsorption of fluoride ion on to $\gamma$ alumina surface at all fluoride concentrations. Computed values from Langmuir isotherm along with their correlation coefficient were presented in Table 2

The Freundlich isotherm was employed for modeling adsorption on heterogeneous surface in dilute solutions. 


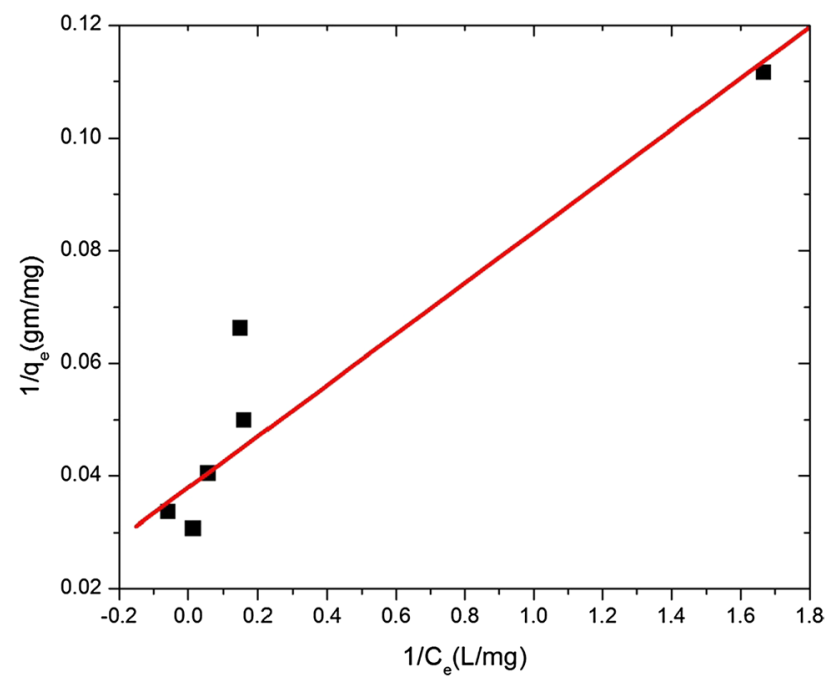

Fig. 11 Langmuir Isotherm for fluoride sorption by nano sized $\gamma$ alumina

Table 2 Langmuir and Freundlich isotherm data of nanosized $\gamma$ alumina

\begin{tabular}{lllll}
\hline Langmuir & & & Freundlich \\
\cline { 5 - 5 }$q_{\max } \mathrm{mg} / \mathrm{g}$ & 26.35 & & 3.34 \\
\hline$b \mathrm{~L} / \mathrm{mg}$ & 0.836 & & $K_{\mathrm{F}}(\mathrm{mg} / \mathrm{g})(\mathrm{mg} / \mathrm{L})-1 / n$ & 10.04 \\
$R^{2}$ & 0.92 & & $R^{2}$ \\
$\chi^{2}$ & 9.4 & $\chi^{2}$ & 0.99 \\
\hline
\end{tabular}

The linear form of Freundlich isotherm can be expressed by the following equation

$\log q_{\mathrm{e}}=\log K_{\mathrm{F}}+\frac{1}{n} \log c_{\mathrm{e}}$

where $K_{\mathrm{F}}$ is the measure for the sorption capacity and 1/ $n$ (heterogeneity factor) indicates adsorption intensity of the adsorbent.

The Freundlich empirical constants, $n$ and $K_{\mathrm{f}}$ were found using linear regression analysis of the relation between $\log$ $\left(c_{\mathrm{e}}\right)$ and $\log \left(q_{\mathrm{e}}\right)$ Fig. 12. They were calculated to be 3.34 $\mathrm{L} / \mathrm{g}$ and $10.04 \mathrm{mg} / \mathrm{g}$, respectively. The $\mathrm{n}$ value, lying in between 1 and 10 supported the favorable adsorption of fluoride on to nano sized $\gamma$-alumina. These computed values along with its correlation coefficient value were presented in Table 2.

\section{$\chi^{2}$ analysis}

This analysis was carried out to identify a appropriate isotherm model for the sorption of fluoride on nano sized $\gamma$ alumina. The equivalent mathematical statement is as given below

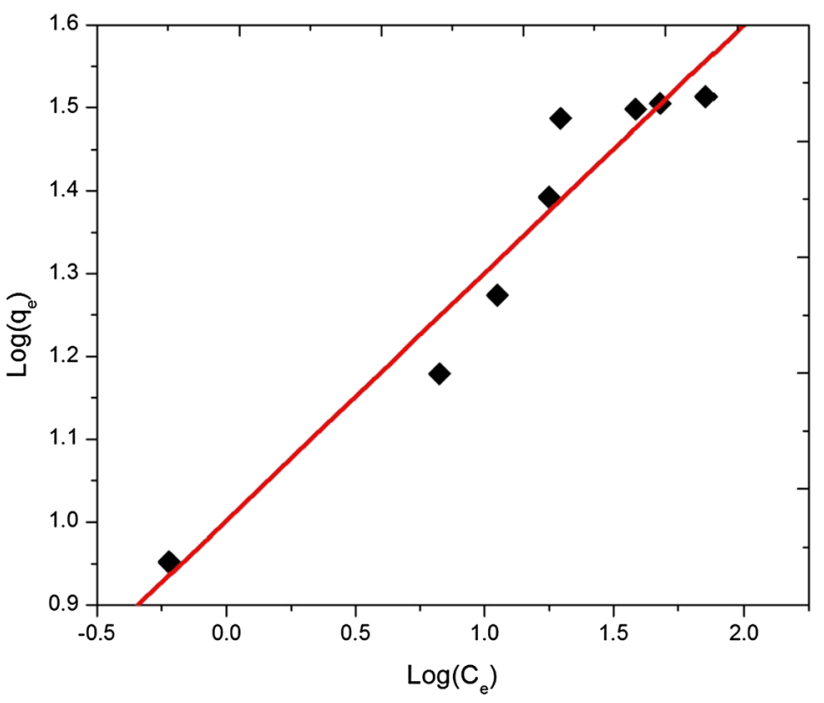

Fig. 12 Freundlich Isotherm for fluoride adsorption on nano sized $\gamma$ alumina

$\chi^{2}=\sum \frac{\left(q_{\mathrm{e}, \text { exp }}-q_{\mathrm{e}, \text { model } l}\right)^{2}}{q_{\mathrm{e}, \text { model }}}$

where $q_{\mathrm{e}, \text { model }}(\mathrm{mg} / \mathrm{g}), q_{\mathrm{e}, \text { exp }}(\mathrm{mg} / \mathrm{g})$ are the equilibrium adsorption capacity derived from the model and from the experimental data, respectively.

If data from the the model are similar to the experimental data, $\chi^{2}$ will be a small number, while if they differ, $\chi^{2}$ would be a bigger number. Therefore, it is necessary to analyze the data set using the non-linear $\chi^{2}$-test to confirm the best-fit isotherm for the sorption system (Unuabonah et al. 2007).

The results obtained from $\chi^{2}$ analysis were presented in Table 2. It was evident from the Table 2, that Freundlich isotherm with smaller $\chi^{2}$ value and correlation coefficient much closer to unity described the equilibrium sorption data better than the Langmuir isotherm. This indicates that, the active sites of the adsorbent were heterogeneously distributed and the fluoride adsorption was mainly through chemisorptions process. Similar results were also observed by earlier researchers (Sundaram et al. 2009).

\section{Effect of temperature and thermodynamic parameters of adsorption}

To study the effect of temperature on adsorption of fluoride by nano $\gamma$-alumina,adsorption experiments were conducted at different temperatures. A comparison of defluoridation capacity with an initial fluoride concentration of $13 \mathrm{mg} / \mathrm{L}$ at three different temperatures 308,318 and $328 \mathrm{~K}$ indicated that influence of temperature variation on fluoride 


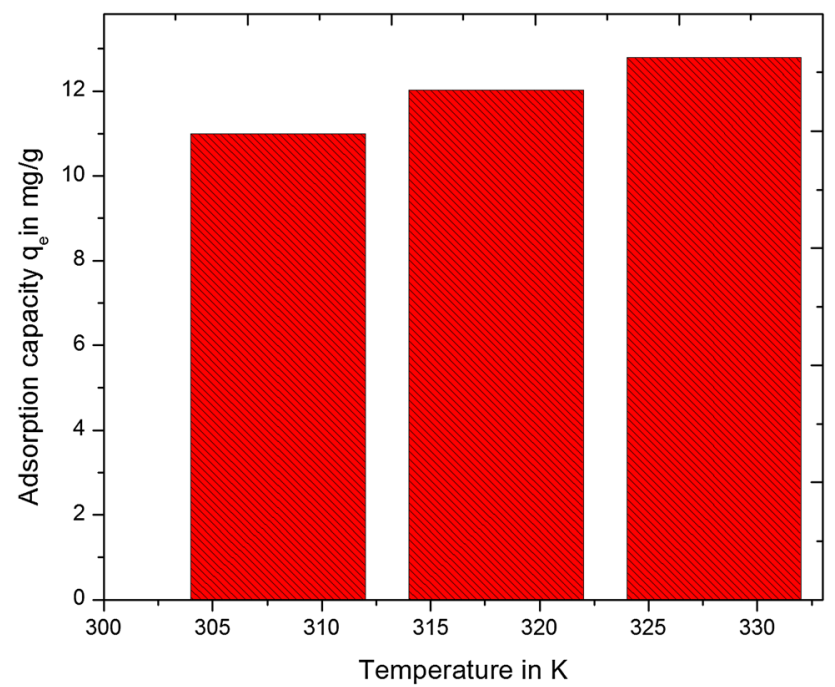

Fig. 13 Effect of temperature on adsorption capacity of nano sized gamma alumina

Table 3 Thermodynamic parameters of nano sized $\gamma$-alumina

\begin{tabular}{lllll}
\hline$\Delta H^{o}\left(\mathrm{~J} \mathrm{~mol}^{-1}\right)$ & $\Delta S^{o}\left(\mathrm{~J} \mathrm{~mol}^{-1} \mathrm{~K}^{-1}\right)$ & $\Delta G^{o}\left(\mathrm{~J} \mathrm{~mol}^{-1}\right)$ & \\
\cline { 3 - 5 } & & $35^{\circ} \mathrm{C}$ & $45^{\circ} \mathrm{C}$ & $55^{\circ} \mathrm{C}$ \\
\hline 70297.2 & 240.737 & -67117.8 & -69525.2 & -71932.5
\end{tabular}

adsorption by nano $\gamma$-alumina was not significant (Fig. 13). Obtained data was further used to calculate potential thermodynamic parameters of the adsorption process, namely standard free energy change $\Delta G^{\mathrm{o}}$,standard enthalpy change $\Delta H^{\circ}$ and standard entropy change $\Delta S^{\circ}$.The following equations were employed to calculate these parameters.

$\log \left(\frac{q_{\mathrm{e}}}{C e}\right)=\frac{\Delta S^{\mathrm{o}}}{2.303 R}-\left(\frac{\Delta H^{\mathrm{o}}}{2.303 R}\right) \frac{1}{T}$

$\Delta G^{\mathrm{o}}=\Delta H^{\mathrm{o}}-T \Delta S^{\mathrm{o}}$

where $q_{\mathrm{e}} / C_{\mathrm{e}}$ represents affinity for fluoride adsorption, $T$ the absolute temperature and $R$ the universal gas constant .

$\Delta H^{\circ}$ and $\Delta S^{\circ}$ were determined from linear regression analysis of the plot $\log \left(q_{\mathrm{e}} / C_{\mathrm{e}}\right)$ versus $1 / T . \Delta G$ was further calculated using the Eq. (11). Obtained values were presented in Table 3. The negative values of $\Delta G$ showed that, fluoride adsorption onto $\gamma$-alumina was a spontaneous process. This is well in accordance with the kinetic studies, Sect. 3.2. Endothermic nature of adsorption of fluoride on to nano $\gamma$-alumina was indicated by the positive value of $\Delta H^{\mathrm{o}}\left(70297.2 \mathrm{~J} \mathrm{~mol}^{-1}\right)$. Affinity of nano $\gamma$-alumina for fluoride was confirmed by the positive value of entropy $\left(\Delta S^{\circ}\right)$.

\section{Comparison of adsorption capacity of nano sized $\gamma$-alumina with other alumina based materials used for defluoridation}

In order to evaluate the fluoride adsorption potential of nano sized $\gamma$-alumina, produced in the current study, a comparative assessment was done between this adsorbent and many other alumina based adsorbents reported earlier, see Table 4. Kumar et al (2011) have used commercially available $\gamma$-alumina for defluoridation studies. nano sized

Table 4 Comparison of fluoride adsorption efficiency of nano- $\gamma$-alumina with various other Aluminium based Adsorbents

\begin{tabular}{|c|c|c|c|}
\hline Adsorbent & Amount adsorbed (mg/g) & Experimental conditions & References \\
\hline Activated alumina & 2.41 & $\begin{array}{l}\text { Concentration: } 2.5-14 \mathrm{mg} / \mathrm{L} \\
\text { Temparature: } 2{ }^{\circ} \mathrm{C}, \mathrm{pH}: 7\end{array}$ & Ghorai and Pant (2005) \\
\hline Nano aluminium oxide hydroxide & 3.26 & $\begin{array}{l}\text { Concentration: } 3-35 \mathrm{mg} / \mathrm{L} \\
\text { Temparature: } 25{ }^{\circ} \mathrm{C}, \mathrm{pH}: 6.8\end{array}$ & Wang et al. (2009) \\
\hline Nano magnesium aluminum Mixed Oxide & 10 & $\begin{array}{l}\text { Concentration: } 1-120 \mathrm{mg} / \mathrm{L} \\
\text { Temparature: } 25{ }^{\circ} \mathrm{C}, \mathrm{pH}: 6.0\end{array}$ & Shukla et al. (2010) \\
\hline Amorphous alumina supported carbon nano tubes & 28.5 & $\begin{array}{l}\text { Concentration: } 50 \mathrm{mg} / \mathrm{L} \\
\text { Temparature: } 30{ }^{\circ} \mathrm{C}, \mathrm{pH}: 6\end{array}$ & Li et al. (2001) \\
\hline Copper oxide coated alumina & 7.23 & $\begin{array}{l}\text { Concentration: } 10 \mathrm{mg} / \mathrm{L} \\
\text { Temparature: } 30{ }^{\circ} \mathrm{C}, \mathrm{pH}: 6.4\end{array}$ & Bansiwal et al. (2010) \\
\hline $\mathrm{Al}(\mathrm{III})$ modified calcium hydroxyapatite & 26.95 & $\begin{array}{l}\text { Concentration: } 5-50 \mathrm{mg} / \mathrm{L} \\
\text { Temparature: } 15^{\circ} \mathrm{C}, \mathrm{pH}: 7\end{array}$ & Nie et al. (2012) \\
\hline Nano- $\mathrm{Al}_{2} \mathrm{O}_{3}$ & 14.0 & $\begin{array}{l}\text { Concentration: } 1-100 \mathrm{mg} / \mathrm{L} \\
\text { Temparature: } 25{ }^{\circ} \mathrm{C}, \mathrm{pH}: 6.15\end{array}$ & Kumar et al. (2011) \\
\hline Nano sized $\gamma$-alumina & 32 & $\begin{array}{l}\text { Concentration: } 50 \mathrm{mg} / \mathrm{L} \\
\text { Temparature: } 30^{\circ} \mathrm{C}, \mathrm{pH}: 4\end{array}$ & Present study \\
\hline
\end{tabular}


$\gamma$-alumina synthesized in this work possessed higher defluoridation capacity (DC) of $32 \mathrm{mgF}^{-} / \mathrm{g}$ and surface area of $221 \mathrm{~m}^{2} / \mathrm{g}$ than commercially available $\gamma$-alumina which showed a DC of $16.38 \mathrm{mg} \mathrm{F}^{-} / \mathrm{g}$ and surface area of $150 \mathrm{~m}^{2} / \mathrm{g}$. It is evident from Table 4 that the nano sized $\gamma$ alumina produced in this work possessed a superior fluoride adsorption capacity than many other similar alumina based adsorbents and commercially available nano- $\gamma$-alumina reported in the literature.

\section{Regeneration and re usability of nano- $\gamma$-alumina}

An adsorbent is considered as cost-effective, if it can be reused for further fluoride adsorption. The reusability of an adsorbent mainly depends on the ease with which adsorbate is released from the exhausted adsorbent. Hence regeneration of any exhausted adsorbent is an essential factor in order to make the sorption process economic.

Fresh nano- $\gamma$-alumina with a dosage of $2 \mathrm{~g} / \mathrm{L}$ was added to fluoride solution of $20 \mathrm{mg} / \mathrm{L}$ concentration. Adsorption was carried out for $2 \mathrm{~h}$ of contact time at $\mathrm{pH}$ 4.After the equilibration gama alumina was separated from the aqueous solution, dried and termed as exhausted or fluoride loaded adsorbent. Fluoride loaded gama alumina was regenerated with the use of $0.1 \mathrm{M} \mathrm{NaOH}$ as eluent. $\mathrm{NaOH}$ elutes fluoride from exhausted gama alumina as $\mathrm{NaF}$. In a typical regeneration experiment "exhausted adsorbent was soaked in a $0.1 \mathrm{M} \mathrm{NaOH}$ for $24 \mathrm{~h}$. The adsorbent was filtered and washed with $0.1 \mathrm{M}$ $\mathrm{HCl}$ solution and deionized water, dried, and used as the regenerated adsorbent. The concentration of the fluoride

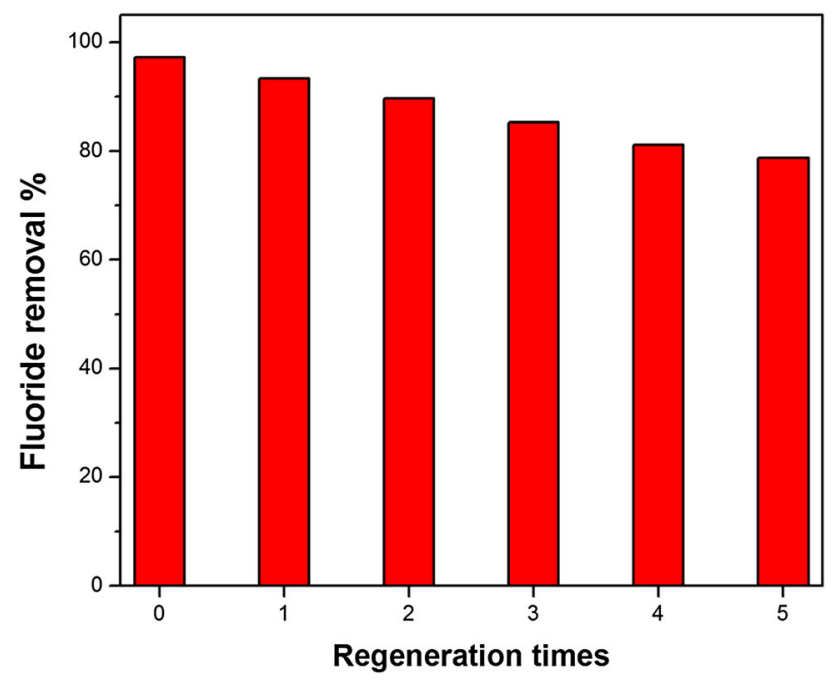

Fig. 14 Percent fluoride removal efficiency of nano- $\gamma$-alumina after each regeneration. (adsorbent dose $=2 \mathrm{~g} / \mathrm{L}$; initial fluoride concentration $=8 \mathrm{mg} / \mathrm{L}$, contact time $2 \mathrm{~h}$ and $\mathrm{pH} 4$ ) desorbed from the nano- $\gamma$-alumina into a $0.1 \mathrm{M} \mathrm{NaOH}$ solution was measured, which was nearly equal to the amount of fluoride adsorbed by the adsorbent" (Chen et al. 2012). The regenerated adsorbent was reused for fluoride adsorption and the exhausted adsorbent was again regenerated and subjected to adsorption studies. In the present study gama alumina was recycled for 5 times. Percent fluoride adsorption was estimated after each recycle and results were presented in Fig. 14. The fluoride removal percentage was calculated as discussed in Sect. 2.4. It was observed that the fluoride removal efficiency by recycled nano- $\gamma$-alumina was nearly $80 \%$ even after 5 regeneration cycles. It is remarkable to note that the decrease in percent fluoride removal efficiency was only $4-5 \%$ in each regeneration cycle. These results indicated that nano- $\gamma$-alumina could be regenerated and reused to treat fluoride contaminated water.

\section{Conclusions}

Using a simple and low cost, surfactant assisted solution combustion method, it was possible to produce ultrafine and highly crystalline nano sized- $\gamma$-alumina particles.

The adsorption of fluoride by nano- $\gamma$-alumina was found to depend on the $\mathrm{pH}$ of fluoride solution and exhibited good adsorption, in the wide $\mathrm{pH}$ window of 3-10 with maximum removal at $\mathrm{pH} 4$. At this $\mathrm{pH}$ the residual fluoride was found to be as low as $0.3 \mathrm{mg} / \mathrm{L}$ which is within the permissible limit of fluoride in drinking water as per WHO. Freundlich and pseudo second order models successfully described the adsorption isotherm and reaction kinetics data, respectively. Analysis of intra particle diffusion model indicated that the mechanism of fluoride removal by nano sized $\gamma$-alumina was complex and both surface adsorption as well as intra particle diffusion contributed to the adsorption process. Nano sized- $\gamma$-alumina produced in this work had a very high fluoride adsorption capacity of $32 \mathrm{mg} / \mathrm{g}$ compared to that of commercially available $\gamma$-alumina which had an adsorption capacity of $14 \mathrm{mg} / \mathrm{g}$ (Kumar et al. 2011). Besides having high adsorption capacity, nano $\gamma$-alumina of the present study could be regenerated and reused for several times. Results obtained in this study, demonstrated that the nano sized- $\gamma$-alumina was a very efficient and potential candidate for the removal of fluoride ions from water, compared to many aluminium based adsorbents reported earlier.

Acknowledgement The authors are grateful to the founder chancellor, Bhagawan Sri Sathya Sai Baba, Sri Sathya Sai Institute of Higher Learning for his constant inspiration. The authors also acknowledge the financial support from DST-FIST (sanction no. SR/ FST/PSI-172/2012). 
Open Access This article is distributed under the terms of the Creative Commons Attribution 4.0 International License (http:// creativecommons.org/licenses/by/4.0/), which permits unrestricted use, distribution, and reproduction in any medium, provided you give appropriate credit to the original author(s) and the source, provide a link to the Creative Commons license, and indicate if changes were made.

\section{References}

Ali I (2012) New generation adsorbents for water treatment. Chem Rev 112:5073-5091

Bansiwal A, Pillewan P, Biniwale RB, Rayalu SS (2010) Copper oxide incorporated mesoporous alumina for defluoridation of drinking water. Microporous Mesoporous Mater 129:54-61. doi:10.1016/j.micromeso.2009.08.032

Chen L, He S, He B-Y, Wang T-J, Su C-L, Zhang C, Jin Y (2012) Synthesis of iron-doped titanium oxide nanoadsorbent and its adsorption characteristics for fluoride in drinking water. Ind Eng Chem Res 51:13150-13156

Chunduri L, Rattan TM, Molli M, Kamisetti V (2014) Single step preparation of nano size gamma alumina exhibiting enhanced fluoride adsorption. Mater Express 4:235-241

Dayananda D, Sarva VR, Prasad SV, Arunachalam J, Ghosh NN (2014) Preparation of $\mathrm{CaO}$ loaded mesoporous $\mathrm{Al}_{2} \mathrm{O}_{3}$ : efficient adsorbent for fluoride removal from water. Chem Eng $\mathrm{J}$ 248:430-439. doi:10.1016/j.cej.2014.03.064

Demirbas E, Kobya M, Senturk E, Ozkan T (2004) Adsorption kinetics for the removal of chromium (VI) from aqueous solutions on the activated carbons prepared from agricultural wastes 30:533-539

Devi RR, Umlong IM, Raul PK, Das B, Banerjee S, Singh L (2014) Defluoridation of water using nano-magnesium oxide. J Exp Nanosci 9:512-524

Eswar P, Devaraj C (2011) Water defluoridation: field studies in India. Indian J Dent Adv 3:526-533

Freundlich HZ (1906) Over the adsorption in solution. Journal of Physical Chemistry 385-470

Ghorai S, Pant KK (2005) Equilibrium, kinetics and breakthrough studies for adsorption of fluoride on activated alumina. Sep Purif Technol 42:265-271. doi:10.1016/j.seppur.2004.09.001

Ho YS, McKay G (1999) Pseudo-second order model for sorption processes. Process Biochem 34:451-465. doi:10.1016/S00329592(98)00112-5

Hu C, Lo S, Kuan W (2005) Effects of the molar ratio of hydroxide and fluoride to $\mathrm{Al}(\mathrm{III})$ on fluoride removal by coagulation and electrocoagulation. J Coll Interface Sci 283:472-476

Kumar E, Bhatnagar A, Kumar U, Sillanpää M (2011) Defluoridation from aqueous solutions by nano-alumina: characterization and sorption studies. J Hazard Mater 186:1042-1049

Langmuir I (1916) The constitution and fundamental properties of solids and liquids. Part i. Solids. J Am Chem Soc 38:2221-2295

Li Y-H et al (2001) Adsorption of fluoride from water by amorphous alumina supported on carbon nano tubes. Chem Phys Lett 350:412-416. doi:10.1016/S0009-2614(01)01351-3
Liu Q, Zhang L, Yang B, Huang R (2015) Removal of fluoride from aqueous solution using $\mathrm{Zr}$ (IV) immobilized cross-linked chitosan. Int J Biol Macromol 77:15-23

Lv L, He J, Wei M, Evans DG, Zhou Z (2007) Treatment of high fluoride concentration water by $\mathrm{MgAl}-\mathrm{CO}_{3}$ layered double hydroxides: kinetic and equilibrium studies. Water Res 41:1534-1542. doi:10.1016/j.watres.2006.12.033

Lv G, Wu L, Liao L, Zhang Y, Li Z (2013) Preparation and characterization of red mud sintered porous materials for water defluoridation. Appl Clay Sci 74:95-101

Mohan D, Sharma R, Singh VK, Steele P, Pittman CU Jr (2012) Fluoride removal from water using bio-char, a green waste, lowcost adsorbent: equilibrium uptake and sorption dynamics modeling. Ind Eng Chem Res 51:900-914

Murray JJ (1986) Appropriate use of fluorides for human health/ edited by JJ Murray. World health organization Geneva

Nie Y, Hu C, Kong C (2012) Enhanced fluoride adsorption using $\mathrm{Al}(\mathrm{III})$ modified calcium hydroxyapatite. J Hazard Mater 233:194-199

Poinern GEJ, Ghosh MK, Ng Y-J, Issa TB, Anand S, Singh P (2011) Defluoridation behavior of nanostructured hydroxyapatite synthesized through an ultrasonic and microwave combined technique. J Hazard Mater 185:29-37. doi:10.1016/j.jhazmat.2010.08.087

Prathibha C, Sharma B, Chunduri LA, Aditha SK, Rattan T, Venkataramaniah K (2015) Nano calcium-aluminum mixed oxide: a novel and effective material for defluoridation of drinking water. Sep Sci Technol 50:1915-1924

Shukla R, Ramkumar J, Tyagi AK (2010) Nanocrystalline magnesia alumina mixed oxide: efficient defluoridation sorbent. Int $\mathrm{J}$ Nanotechnol 7:989-1002

Sun L, Yuan Z, Gong W, Zhang L, Xu Z, Su G, Han D (2015) The mechanism study of trace $\mathrm{Cr}(\mathrm{VI})$ removal from water using $\mathrm{Fe} 0$ nanorods modified with chitosan in porous anodic alumina. Appl Surf Sci 328:606-613

Sundaram CS, Viswanathan N, Meenakshi S (2009) Defluoridation of water using magnesia/chitosan composite. J Hazard Mater 163:618-624

Unuabonah E, Olu-Owolabi B, Adebowale K, Ofomaja A (2007) Adsorption of lead and cadmium ions from aqueous solutions by tripolyphosphate-impregnated Kaolinite clay. Colloids Surf A 292:202-211

Wang S-G, Ma Y, Shi Y-J, Gong W-X (2009) Defluoridation performance and mechanism of nano-scale aluminum oxide hydroxide in aqueous solution. J Chem Technol Biotechnol 84:1043-1050. doi:10.1002/jctb.2131

WHO (1994) Report of the WHO expert committee on oral health status and fluoride use, vol 846. World Health Organization, Geneva

Wu X, Zhang Y, Dou X, Yang M (2007) Fluoride removal performance of a novel Fe-Al-Ce trimetal oxide adsorbent. Chemosphere 69:1758-1764. doi:10.1016/j.chemosphere.2007. 05.075

Zhang W, Sun M, Prins R (2002) Multinuclear MAS NMR identification of fluorine species on the surface of fluorinated $\gamma$-alumina. J Phys Chem B 106:11805-11809

Zhang Z, Tan Y, Zhong M (2011) Defluorination of wastewater by calcium chloride modified natural zeolite. Desalination 276:246-252 